\title{
Analisis Pendapatan Usaha Nelayan Tangkap Ikan Tuna Di Kabupaten Manokwari
}

\author{
Nurhasana $^{1}$, Achmad Rochani ${ }^{2}$, Ketysia Imelda Tewernusa ${ }^{3}$ \\ ${ }^{1}$ Alumni Jurusan Ekonomi Pembangunan, Universitas Papua \\ ${ }^{2,3}$ Dosen Jurusan Ekonomi Pembangunan, Universitas Papua
}

Received: Maret 2021; Accepted: Maret 2021; Published: Maret 2021

\begin{abstract}
Abstrak
Penelitian ini bertujuan mengetahui dan menganalisis seberapa besar tingkat pendapatan usaha nelayan tangkap ikan tuna dan faktor-faktor apa saja yang mempengaruhi tingkat pendapatan usaha nelayan tangkap ikan tuna di Kabupaten Manokwari. Metode analisis yang digunakan adalah metode Analisis Deskriptif Kuantitatif dengan instrument pedoman wawancara dan kuesioner. Analisis data dilakukan dengan menggunakan alat analisis regresi linear berganda. Hasil penelitian menunjukan bahwa secara simultan dan parsial variabel modal, lama melaut, jumlah tenaga kerja dan pengalama melaut berpengaruh signifikan terhadap pendapatan usaha nelayan tangkap ikan tuna di Kabupaten
\end{abstract} Manokwari.

Kata kunci: pendapatan usaha nelayan tangkap ikan tuna. modal, lama melaut, jumlah tenaga kerja dan pengalaman melaut.

\begin{abstract}
The purpose of his study aims to determine and analyze how much the income level of tuna fishing business is and what factors affect the level of tuna fishing business income in Manokwari Regency. The analytical method used is the quantitative descriptive analysis method with interview guides and questionnaires as instruments. Data analysis was performed using multiple linear regression analysis. The results showed that simultaneously and partially the variables of capital, length of time at sea, number of workers and experience at sea had a significant effect on the income of tuna fishermen in Manokwari Regency.
\end{abstract}

Keywords: tuna fishing business income. capital, length of time at sea, number of workers and experience at sea.

How to Cite: Nurhasana., Rochani, A., Tewernusa, I., K., (2021). Analisis Pendapatan Usaha Nelayan Tangkap Ikan Tuna Di Kabupaten Manokwari JFRES: Journal of Fiscal and Regional Economy Studies, 4 (1), $61-67$. 


\section{PENDAHULUAN}

Indonesia merupakan negara kepulauan terbesar di dunia, yang terdiri dari 5 (lima) pulau besar dan 30 (tiga puluh) kepulauan kecil, jumlah keseluruhan tercatat 17.504 pulau, yang terdiri dari 8.651 pulau sudah bernama, 8.853 pulau belum bernama, dan 9.842 pulau yang telah diverifikasi. Kondisi geografis yang strategis terbentang sepanjang $5.250 \mathrm{~km}^{2}$ diantara benua Australia dan Asia serta membelah Samudra Hindia dan Samudra Pasifik di bawah garis khatulistiwa. Wilayah Negara Republik Indonesia meliputi wilayah daratan dan wilayah air yang meliputi: perairan pedalaman, perairan kepulauan, laut dan ruang udara diatasnya, termasuk seluruh sumber kekayaan yang terkandung di dalamnya.

Manokwari merupakan ibu kota Provinsi Papua Barat yang memiliki luas wilayah $1.556,94 \mathrm{~km}^{2}$ dan berpenduduk kurang lebih 99.488 jiwa. Kabupaten Manokwari memiliki keunggulan alam secara geografis salah satunya di bidang perikanan. Jumlah nelayan tangkap di Kabupaten Manokwari menurut Distrik Tahun 2016 dapat dilihat pada tabel 1.

Tabel 1. Jumlah Nelayan Tangkap di Kabupaten Manokwari Tahun 2016

\begin{tabular}{llrr}
\hline No & Distrik & $\begin{array}{c}\text { Jumlah } \\
\text { (RT) }\end{array}$ & $\begin{array}{c}\text { Nisba } \\
\text { h (\%) }\end{array}$ \\
\hline 1 & Manokwari Barat & 275 & 35,94 \\
\hline 2 & Manokwari Timur & 200 & 26,14 \\
\hline 3 & Manokwari Utara & 108 & 14,11 \\
\hline 4 & Manokwari Selatan & 72 & 9,41 \\
\hline 5 & Tanah Rubuh & 54 & 7,05 \\
\hline 6 & Masni & 31 & 4,05 \\
\hline 7 & Sidey & 25 & 3,26 \\
\hline & Total & $\mathbf{7 6 5}$ & $\mathbf{1 0 0}$ \\
\hline
\end{tabular}

\section{Sumber: BPS Kab. Manokwari, 2017}

Dari tabel 1 dapat di lihat bahwa konsentrasi nelayan tangkap di Kabupaten Manokwari terdapat di 3 (tiga) distrik, yaitu distrik Manokwari Barat, distrik Manokwari Timur, dan distrik Manokwari Utara, yang mencapai $76 \%$ dari seluruh nelayan tangkap di Kabupaten Manokwari. Jumlah nelayan tangkap sebanyak 275 rumah tangga di distrik Manokwari Barat. Nelayan tangkap di distrik Manokwari Barat umumnya bermukim di Kelurahan Padarni dan Kampung Wirsi di sekeliling Teluk
Sawaibu.

Tabel 2. Jumlah Produksi Perikanan Menurut Jenis Ikan di Kabupaten Manokwari Tahun 2014-2016

\begin{tabular}{|c|c|c|c|c|}
\hline No & Jenis Ikan & $\begin{array}{c}\text { Perikana } \\
\text { n Laut }\end{array}$ & $\begin{array}{c}\text { Perikanan } \\
\text { Darat }\end{array}$ & Jumlah \\
\hline 1 & $\begin{array}{l}\text { Ikan merah/ } \\
\text { Bambangan }\end{array}$ & 2,563 & 0 & $2,563,00$ \\
\hline 2 & $\begin{array}{c}\text { Lencam/ } \\
\text { Sikuda }\end{array}$ & 256,70 & 0 & 256,70 \\
\hline 3 & Kakap/ Geropa & 13,80 & 0 & 163,80 \\
\hline 4 & $\begin{array}{c}\text { Ekor kuning/ } \\
\text { Tuna }\end{array}$ & $11,210,55$ & $\mathbf{0}$ & $\begin{array}{r}11,210,6 \\
0\end{array}$ \\
\hline 5 & Pisang-pisang & 88,50 & 0 & 88,50 \\
\hline 6 & Cucut & 13,65 & 0 & 13,70 \\
\hline 7 & Alu-alu & 91,00 & 0 & 91,00 \\
\hline 8 & Layang & $1,092,00$ & 0 & $1,092,00$ \\
\hline 9 & Selar & 754,65 & 0 & 754,70 \\
\hline 10 & Kuwe & 332,80 & 0 & 332,80 \\
\hline 11 & Sunglir & 421,20 & 0 & 421,20 \\
\hline 12 & Julung-Julung & 193,70 & 0 & 193,70 \\
\hline 13 & Teri & 26,00 & 0 & 26,00 \\
\hline 14 & Lemuru & 93,60 & 0 & 93,60 \\
\hline 15 & Tenggiri & 598,00 & 0 & 598,00 \\
\hline 16 & Kembung & 468,00 & 0 & 468,00 \\
\hline 17 & Cakalang & $5,163,60$ & 0 & $5,136,60$ \\
\hline 18 & Tongkol & 565,50 & 0 & 565,50 \\
\hline 19 & Cumi-cumi & 130,00 & 0 & 130,00 \\
\hline 20 & Gurita & 33,15 & 0 & 33,20 \\
\hline 21 & $\begin{array}{c}\text { Baronang/ } \\
\text { samandar }\end{array}$ & 113,75 & 0 & 113,80 \\
\hline 22 & Biji Nangka & 13,00 & 0 & 13,00 \\
\hline 23 & Kerapu & 988,00 & 0 & 988,00 \\
\hline 24 & Udang & 0 & 0 & 0 \\
\hline 26 & Ikan Mas & 0 & 162,50 & 162,50 \\
\hline 27 & Mujair & 0 & 300,00 & 300,00 \\
\hline 28 & Lele & 0 & 20,00 & 20,00 \\
\hline 29 & Nila & 0 & 290,00 & 290,00 \\
\hline \multirow[t]{3}{*}{ Total } & 2016 & $25,045,85$ & 772,50 & $\begin{array}{r}26,233,3 \\
5\end{array}$ \\
\hline & 2015 & $25,50,85$ & 573,30 & $\begin{array}{r}26,024,2 \\
4 \\
\end{array}$ \\
\hline & 2014 & $1,226,10$ & 441,00 & $1,667,10$ \\
\hline
\end{tabular}

Sumber :BPS Kab. Manokwari, 2017

Ikan tuna merupakan salah satu komoditas primadona di Kabupaten Manokwari, setidaknya dilihat peran sektor perikanan dalam pangsa ekspor khususnya ekspor komoditas untuk jenis ikan tuna. Kawasan perairan wilayah Kabupaten Manokwari sangat potensial akan jenis ikan tersebut.

Dari tabel 2 dapat dilihat bahwa ikan tuna merupakan salah satu jenis ikan yang menjadi primadona di Kabupaten Manokwari. Produksi ikan tuna di Kabupaten Manokwari tahun 2014-2016 produk sebesar 11,210.60 ton, produksi ikan tuna melebihi produksi jenis ikan yang lain di Kabupaten Manokwari.

Tujuan penelitian ini adalah untuk 
mengetahui tingkat pendapatan nelayan dan faktor-faktor yang mempengaruhi tingkat pendapatan usaha nelayan tangkap ikan tuna di Kelurahan Pardani dan Kampung Wirsi di Sekeliling Teluk Sawaibu Kabupaten Manokwari.

\section{METODE PENELITIAN}

Penelitian ini dilakukan di Kelurahan Padarni dan Kampung Wirsi di Sekeliling Teluk Sawaibu di Kabupaten Manokwari Subjek dalam penelitian ini adalah nelayan yang berada di Kelurahan Padarni dan Kampung Wirsi di sekeliling Teluk sawaibu yang langsung menangkap ikan tuna dan menjual hasil tangkapan ikan tuna di pasar ikan sanggeng Kabupaten Manokwari. Objek dalam penelitian ini adalah tingkat pendapatan dari nelayan yang berada di Kelurahan Padarni dan Kampung Wirsi di Sekeliling Teluk Sawaibu Kabupaten Manokwari.

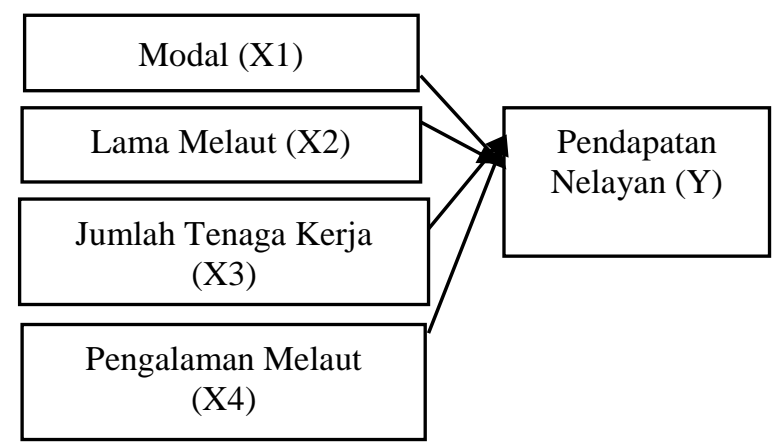

Keterangan: $\longrightarrow=$ Mempengaruhi

Gambar 1. Kerangka Pemikiran

Berdasarkan perumusan masalah dan kerangka pemikiran maka dibuat hipotesis sebagai berikut :

H0: Diduga variabelmodal, lama melaut, jumlah tenaga kerja dan pengalaman melaut tidak berpengaruh positif dan signifikan terhadap pendapatan nelayan tangkap ikan tuna.

Ha: Diduga variabel modal, lama melaut, jumlah tenaga kerja dan pengalaman melaut berpengaruh positif dan signifikan terhadap pendapatan nelayan tangkap ikan tuna.

Populasi dalam penelitian ini adalah nelayan yang berada di Kelurahan Padarni dan Kampung Wirsi di sekeliling Teluk Sawaibu sebanyak 273 nelayan. Sampel adalah sebagian dari jumlah dan karakteristik yang dimiliki oleh populasi tersebut. Teknik sampling yang dingunakan dalam penentuan sampel adalah dengan teknik purposive sampling yaitu, teknik pengambilan secara sengaja sesuai dengan persyaratan sampel yang diperlukan. Teknik purposive sampling dilakukan karena kosentrasi nelayan terbanyak di Kabupaten Manokwari berada di Kelurahan Padarni dan Kampung Wirsi di Sekeliling Teluk sawaibu. Sampel dalam penelitian ini adalah sebagian dari jumlah nelayan di Kelurahan Padarni dan Kampung Wirsi di Sekeliling Teluk Sawaibu yaitu sebanyak 73 sampel dengan menggunakan rumus Slovin.

Model analisis yang digunakan untuk menganalis data adalah dengan metode Ordinary Least Square $(O L S)$ dimana pengolahan data dilakukan dengan program SPSS 16. Metode analisis yang digunakan untuk menggambarkan hubungan antara variabel terikat dengan variabel bebasnya adalah dengan menggunakan model regresi berganda atau multiple regression (Bachtiar, 2012). Variabel bebas dalam penelitian ini adalah modal, lama melaut, jumlah tenaga kerja dan pengalaman melaut, sedangkan variabel terikatnya adalah pendapatan nelayan tangkap ikan tuna. Pengujian data dalam peneltian ini meliputi uji asumsi klasik, uji statistik dan uji koefisisen determinasi.

\section{HASIL DAN PEMBAHASAN}

Karakteristik responden dalam penelitian ini meliputi karakteristik responden menurut umur, status perkawinan, tingkat pendidikan, modal awal, lama melaut, jumlah tenaga kerja, pengalaman melaut, dan berdasarkan pendapatan nelayan tangkap ikan tuna.

\section{Pendapatan Usaha Tangkap Ikan Tuna Per Trip}

Pendapatan diperoleh responden dari total penerimaan pertrip di kurangi dengan total biaya pertrip. Pendapatan nelayan tangkap ikan tuna di Kelurahan Padarni dan Kampung Wirsi di Sekeliling Teluk Sawaibu dapat dilihat pada tabel 3. Tabel 3 menggambarkan bahwa rata-rata pendapatan bersih nelayan tangkap ikan tuna sebesar Rp. 6.479.240 per trip. Berdasarkan hasil penelitian diketahui bahwa upah tenaga kerja yang diterima oleh nelayan tangkap ikan tuna diterima pada sistem bagi hasil, sistem bagi hasil pendapatan berupa upah untuk nelayan tangkap ikan tuna, pendapatan bersih per trip yakni penerimaan - biaya total. Jika dalam satu perahu terdiri dari 3 orang tenaga kerja 1 orang juragang, dan 2 orang tenaga kerja maka sistem bagi hasilnya di bagi 5 (termasuk perahu dan mesin), jika jumlah tenaga kerja dalam 1 perahu tenaga 
kerja 1 orang maka sistem bagi hasilnya dibagi 4 (juragan, tenaga kerja, perahu dan mesin).

Tabel 3. Rata-rata Pendapatan Usaha Nelayan Tangkap Ikan Tuna Per Trip

\begin{tabular}{lrr}
\hline No & Uraian & \multicolumn{1}{c}{$\begin{array}{c}\text { Jumlah } \\
\text { (Per trip/Rp) }\end{array}$} \\
\hline 1 & Penerimaan & 14.654 .041 \\
\hline 2 & Biaya operasional & 4.913 .493 \\
& Upah tenaga kerja & 3.261 .308 \\
\hline & Biaya total & 8.174 .801 \\
\hline & Pendapatan & 6.479 .240 \\
\hline Maksimum & 15.285 .000 \\
\hline Minimum & 150.000 \\
\hline Rata-rata & 6.479 .240 \\
\hline
\end{tabular}

Sumber: Data Primer diolah, 2018

\section{Analisis Regresi Linear berganda}

Analisis regresi linear berkaitan dengan suatu variabel dependen dengan satu variabel atau lebih variabel independen. Tujuan dari diadakannya penelitian ini adalah untuk mengetahui faktor Modal (X1), Lama melaut (X2), Jumlah tenaga kerja (X3), Pengalaman melaut (X4) terhadap pendapatan nelayan tangkap ikan tuna (Y) pengaruh tersebut akan dapat diketahui dengan menggunakan analisis regresi linear berganda. Adapun hasil persamaan regresi linear berganda yang diperoleh adalah sebagai berikut :

$$
\begin{gathered}
\mathrm{Y}=18.180+0.057(\mathrm{X} 1)+0.168(\mathrm{X} 2)+2.822(\mathrm{X3})+ \\
\mathbf{0 . 4 2 6}(\mathrm{X} 4)+\mathrm{e}
\end{gathered}
$$

Dari persamaan di atas dapat diketahui bahwa nilai konstanta untuk empat variabel sebesar 18.180 dan variabel independen modal diartikan sebagai modal usaha yang dingunakan adalah nilai satuan rupiah, dimana nilai koefisien regresi sebesar 0.057 , artinya jika modal kerja meningkat 1 rupiah maka pendapatan nelayan tangkap ikan tuna meningkat sebesar 0.057 rupiah. Variabel lama melaut dimana satuan yang dingunakan adalah hari dan memiliki nilai koefisien regresi sebesar 0.168, artinya jika lama melaut meningkat 1 hari maka pendapatan nelayan tangkap ikan tuna meningkat sebesar 0.168 rupiah.

Variabel jumlah tenaga kerja dengan skala pengukuran yang dingunakan adalah satuan orang dan memiliki nilai koefisien regresi sebesar 2.822 artinya jika jumlah tenaga kerja meningkat 1 orangmaka pendapatan nelayan tangkap ikan tuna meningkat sebesar 2.822 rupiah. Variabel pengalaman melaut dimana pengalaman melaut memiliki nilai satuan tahun dan memiliki nilai koefisien regresi sebesar 0.426 artinya jika pengalaman melaut meningkat 1 tahun maka pendapatan nelayan tangkap ikan tuna meningkat sebesar 0.426 rupiah.

\section{Hasil Uji Asumsi Klasik}

\section{Uji Heteroskedastisitas}

Uji heteroskedastisitas dilakukan untuk menguji apakah dalam sebuah model regresi terjadi ketidaksamaan varians dari residual dari satu pengamatan ke pengamatan yang lain jika varians dan residu dari satu pengalaman ke pengalaman lain tetap, maka di sebut homokedastisitas, dan jika varians berbeda disebut heteroskedastisitas. Model regresi yang baik adalah tidak terjadi heteroskedastisitas. Santoso (2000). Deteksi heteroskedastisitas dapat dilakukan dengan metode Scatter Plot dengan memplotkan nilai ZPRED (nilai prediksi) dengan SRESID (nilai residualnya). Model yang baik didapatkan jika tidak terdapat pola tertentu pada grafik, seperti mengumpul di tengah, menyempit kemudian melebar atau sebaliknya melebar kemudian menyempit, mengindikasikan terjadi heteroskedastisitas. Sebaliknya jika pola yang jelas, serta titik-titik menyebar di atas dan di bawah angka 0 pada sumbu Y, maka tidak terjadi masalah heteroskedastisitas.

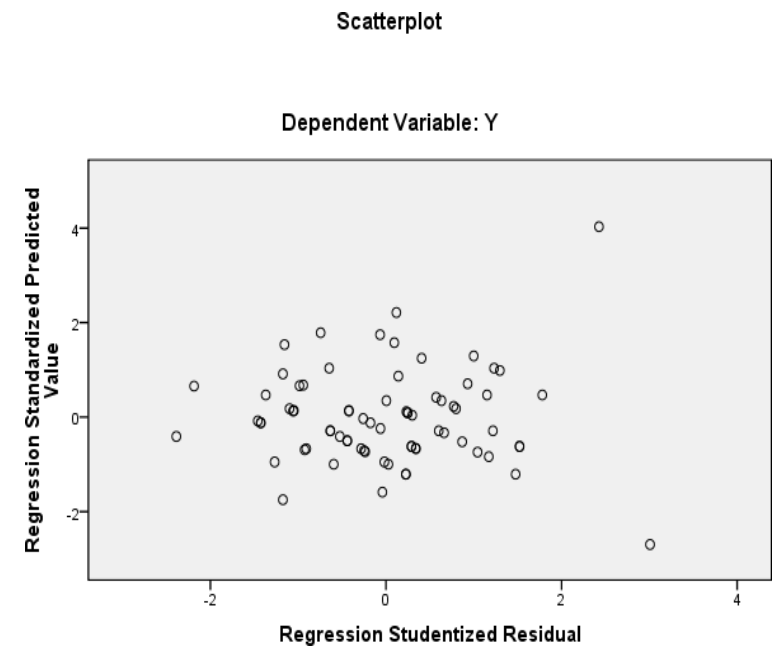

Sumber: Data Primer diolah, 2018

Gambar 2. Grafik Scatterplot

Berdasarkan gambar 2 terlihat titik secara acak serta tersebar baik diatas maupun di bawah angka 0 pada sumbu Y serta tidak membentuk pola atau kecenderungan tertentu pada diagram plot, sehingga dapat disimpulkan bahwa tidak terjadi heteroskedastisitas pada model regresi. 


\section{Uji Normalitas}

Pengujian ini bertujuan untuk menguji variabel terikat dan variabel bebas dalam model regresi yang mempunyai distribusi normal atau tidak. Model regresi yang baik adalah yang memiliki distribusi data normal atau yang mendekati normal pengambilan kesimpulan dengan melihat tampilan grafik histogram, apabila histogram hampir menyerupai genta dan titik varian semuanya mengikuti arah garis diagonal, menunjukkan model regresi memenuhi asumsi normalitas artinya layak pakai (Ghozali 2006).

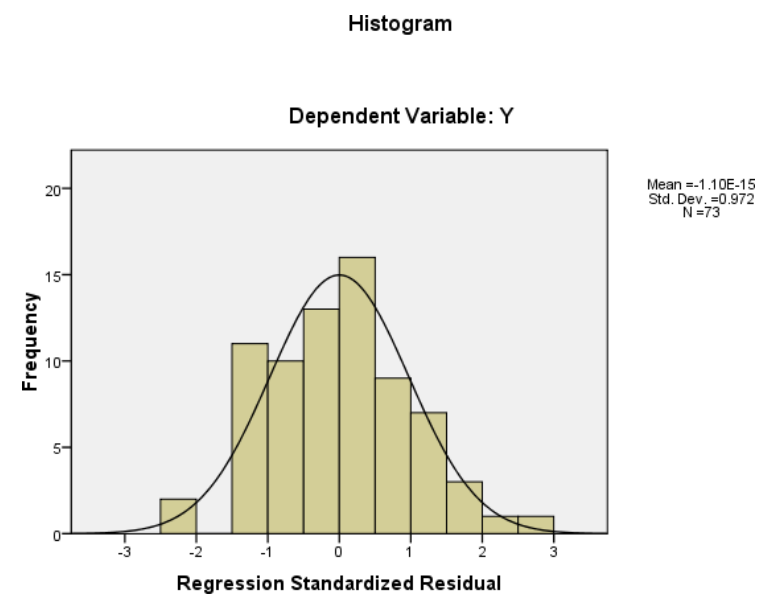

Sumber: Data Primer diolah, 2018

Gambar 3. Grafik Histogram

Normal P-P Plot of Regression Standardized Residual

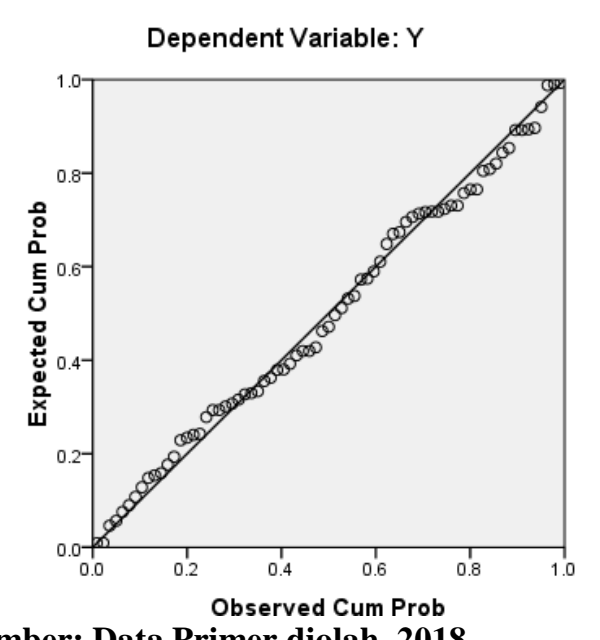

Sumber: Data Primer diolah, 2018

Gambar 4. Normal P-P Of Regression Standardized Residual

Pada gambar dapat dilihat bahwa grafik normal probability plot of regression standardized menunjukan pola grafik yang normal. Hal ini terlihat dari titik-titik yang menyebar di sekitar diagonal dan penyebarannya mengikuti garis diagonal. Dapat disimpulkan bahwa metode regresi layak dipakai karena memenuhi asumsi normalitas.

\section{Uji Multikolinearitas}

Tabel 4 Hasil Uji Multikolinearitas

\begin{tabular}{ccc}
\hline Model & \multicolumn{2}{c}{ Colinearity Statistic } \\
\cline { 2 - 3 } & Tolerance & VIF \\
\hline Modal (X1) & 0.951 & 1.051 \\
\hline Lama melaut (X2) & 0.985 & 1.015 \\
\hline $\begin{array}{c}\text { Jumlah Tenaga } \\
\text { Kerja (X3) }\end{array}$ & 0.970 & 1.031 \\
\hline $\begin{array}{c}\text { Pengalaman Melaut } \\
\text { (X4) }\end{array}$ & 0.935 & 1.070 \\
\hline
\end{tabular}

\section{Sumber: Data Primer diolah, 2018}

Berdasarkan hasil pengujian pada tabel 4 diketahui bahwa nilai tolerance untuk setiap variabel independen tidak ada yang memiliki nilai tolerance $<0.10$ dan nilai VIF untuk setiap variabel tidak ada yang memiliki nilai $>10$. Dari analisis diatas dapat diketahui nilai tolerance dari variabel (X1) variabel modal 0.951 (0.951 > 0.10 ), untuk nilai tolerance dari variable lama melaut (X2) sebesar $0.985(0.985>0.10)$, untuk nilai tolerance dari variabel jumlah tenaga kerja (X3) sebesar $0.970(0.970>0.10)$, dan untuk nilai tolerance dari variabel pengalaman melaut (X4) $0.935(0.935>0.10)$. Sedangkan untuk nilai VIF dari (X1) variabel modal sebesar 1.051 (1.051 < 10), nilai VIF dari (X2) variabel lama melaut sebesar $1.015(1.015<10)$, nilai VIF dari (X3) variabel umlah tenaga kerja sebesar 1.031 (1.031 $<10)$, nilai VIF dari (X4) variabel pengalaman melaut sebesar $1.070(1.070<10)$. Yang artinya berdasarkan pengujian multikonearitas diatas dapat diketahui bahwa semua variabel independen memiliki nilai tolerance lebih besar dari 0.10 dan untuk nilai VIF lebih kecil dari 10. Dengan demikian dapat disimpulkan bahwa variabel independen tidak ada multikonearitas dalam model regresi.

\section{Uji F (Simultan)}

Uji pengaruh simultan digunakan untuk mengetahui apakah variabel independen secara bersama-sama atau simultan mempengaruhi variabel dependen dengan tingkat signifikan 5 persen $(0,05)$. Jika nilai signifikan $<0,05$ maka dapat dikatakan terdapat pengaruh yang signifikan secara bersama-sama antara variabel independent terhadap variabel dependen. 
Tabel 5. Hasil Uji Simultan (Uji F)

\begin{tabular}{|c|c|c|c|c|c|c|}
\hline Model & Sum of Squares & Df & Mean Square & F hitung & F tabel & Sig. \\
\hline Regression & 164.912 & 4 & 41.228 & 15.229 & 2,74 & $0.000^{\mathrm{a}}$ \\
\hline Residual & 183.252 & 68 & 2.695 & & & \\
\hline Total & 348.164 & 72 & & & & \\
\hline
\end{tabular}

Dari hasil pengujian diperoleh nilai $\mathrm{f}_{\text {hitung }}=$ 15.229 dan $\mathrm{f}_{\text {tabel }}=2,74$ dengan signifikansi sebesar 0,00. Oleh karena itu $\mathrm{f}_{\text {hitung }}(15.229>$ $2,74)$, dengan nilai signifikansi lebih kecil dari $0,05(0,00<0,05)$, maka $\mathrm{HO}$ di tolak dan $\mathrm{Ha}$ diterima yang berarti modal, lama melaut, jumlah tenaga kerja, dan pengalaman melaut secara simultan berpengaruh terhadap pendapatan usaha nelayan tangkap ikan tuna.

\section{Uji T (Parsial)}

Pengaruh secara parsial variabel modal, lama melaut, jumlah tenaga kerja dan pengalaman melaut terhadap pendapatan usaha nelayan tangkap ikan tuna adalah sebagai berikut : Dari hasil uji statistik (uji parsial t) nilai koefisien variabel modal adalah 0.057 dan nilai $t_{\text {hitung }}=$ 3.017 sedangkan nilai $t_{\text {tabel }}(\mathrm{df}=69, \alpha=0,05)$ adalah 1995. Dengan demikian maka $t_{\text {hitung }}>t_{\text {tabel }}$ $3.017>1995$ dan sig $0.004<0.05$ jadi H0 ditolak Ha diterima. Sehingga dapat disimpulkan bahwa secara parsial variabel modal berpengaruh positif dan signifikan terhadap pendapatan usaha nelayan tangkap ikan tuna..

Tabel 6. Hasil Uji Parsial (Uji t)

\begin{tabular}{|c|c|c|c|c|c|c|}
\hline \multirow[t]{2}{*}{ Model } & \multicolumn{2}{|c|}{$\begin{array}{c}\text { Unstandardized } \\
\text { Coefficients }\end{array}$} & \multirow{2}{*}{$\begin{array}{l}\begin{array}{l}\text { Standardized } \\
\text { Coefficients }\end{array} \\
\text { Beta } \\
\end{array}$} & \multirow[t]{2}{*}{$\begin{array}{c}\mathrm{T} \\
\text { hitung }\end{array}$} & \multirow[t]{2}{*}{$\begin{array}{c}\mathrm{T} \\
\text { tabel }\end{array}$} & \multirow[t]{2}{*}{ Sig. } \\
\hline & B & Std. Error & & & & \\
\hline (Constant) & 18.180 & 2.544 & & 7.147 & 1.995 & 0.000 \\
\hline Modal & 0.057 & 0.019 & 0.272 & 3 & & 0.004 \\
\hline Lama melaut & 0.168 & 0.060 & 0.140 & 2 & & 0.003 \\
\hline Jumlah tenaga kerja & 2.822 & 0.403 & 0.624 & 6 & & 0.000 \\
\hline Pengalaman melaut & 0.426 & 0.202 & 0.206 & 2 & & 0.039 \\
\hline
\end{tabular}

\section{Sumber: Data Primer diolah, 2018}

Nilai koefisien variabel lama melaut adalah 0.168 dan nilai $\mathrm{t}_{\text {hitung }}=2.813$ sedangkan nilai $\mathrm{t}_{\text {tabel }}(\mathrm{df}=$ $69, \alpha=0,05$ ) adalah 1995, dengan demikian maka thitung $>\mathrm{t}_{\text {tabel }} 2.813>1995$ dan sig $0.003<0.05$ jadi H0 ditolak Ha diterima, sehingga dapat disimpulkan bahwa secara parsial variabel lama melaut berpengaruh positif dan signifikan terhadap pendapatan usaha nelayan tangkap ikan tuna. Nilai koefisien variabel jumlah tenaga kerja adalah 2.822 dan nilai $t_{\text {hitung }}=6.992$ sedangkan nilai $\mathrm{t}_{\text {tabel }}(\mathrm{df}=69, \alpha=0,05)$ adalah 1995 . Dengan demikian maka $t_{\text {hitung }}>t_{\text {tabel }} 6.992>1995$ dan sig $0.000<0.05$ jadi H0 ditolak Ha diterima, sehingga secara parsial variabel jumlah tenaga kerja berpengaruh positif dan signifikan terhadap pendapatan usaha nelayan tangkap ikan tuna. Variabel pengalaman melaut adalah 0.426 dan nilai $\mathrm{t}_{\text {hitung }}=2.120$ sedangkan nilai $\mathrm{t}_{\text {tabel }}(\mathrm{df}=69$, $\alpha=0,05)$ adalah 1995 dengan demikian maka $t_{\text {hitung }}>\mathrm{t}_{\text {tabel }} 2.120>1995$ dan sig $0.039<0.05$ jadi $\mathrm{H} 0$ ditolak $\mathrm{Ha}$ diterima. Sehingga dapat disimpulkan bahwa secara parsial variabel pengalaman melaut berpengaruh positif dan signifikan terhadap pendapatan usaha nelayan tangkap ikan tuna.

\section{Uji Koefisien Determinasi $\left(\mathbf{R}^{2}\right)$}

Koefisien determinasi $\left(\mathrm{R}^{2}\right)$ dimaksudkan untuk mengetahui tingkat ketepatan paling baik dalam analisis regresi, dimana hal ini yang ditunjukan oleh besarnya koefisien determinasi $\left(R^{2}\right)$ yang semakin mendekati satu, maka dapat dikatakan bahwa variabel independent berpengaruh pada variabel dependen.

Tabel 7. Hasil Uji Koefisien Determinasi $\left(\mathrm{R}^{2}\right)$

\begin{tabular}{ccccc}
\hline R & R Square & \multicolumn{2}{c}{$\begin{array}{l}\text { Adjusted R } \\
\text { Square }\end{array}$} & $\begin{array}{l}\text { Std. Error of } \\
\text { the Estimate }\end{array}$ \\
\hline $0.796^{\mathrm{a}}$ & 0.602 & 0.594 & 1.82161 \\
\hline
\end{tabular}

\section{Sumber: Data Primer Diolah, 2018}

Koefisien determinasi $\left(\mathrm{R}^{2}\right)$ menunjukkan pengaruh secara simultan. Besarnya $\mathrm{R}^{2}$ adalah 0,602 hal ini berarti $60,2 \%$ variabel hasil tangkapan ikan tuna dapat dijelaskan 
oleh keempat variabel independent yaitu Modal (X1), Lama melat (X2), Jumlah tenaga kerja (X3), Pengalaman melaut (X4). Sedangkan sisanya 39,8\% dipengaruhi oleh faktor-faktor lain diluar model atau variabel yang diteliti.

\section{KESIMPULAN}

Rata-rata pendapatan pertrip nelayan usaha tangkap ikan di Kelurahan Pardani dan Kampung Wirsi di Sekeliling Teluk Sawaibu Kabupaten Manokwari sebesar Rp. 6.479.240 rupiah dengan kisaran maksimum Rp. 15.285.000 dan minimum Rp. 150.000.

Faktor modal (X1), lama melaut (X2), jumlah tenaga kerja (X3), dan pengalaman melaut (X4) secara parsial dan simultan berpengaruh signifikan terhadap pendapatan usaha nelayan tangkap ikan tuna di Kelurahan Pardani dan
Kampung Wirsi di Sekeliling Teluk Sawaibu Kabupaten Manokwari.

\section{DAFTAR PUSTAKA}

Bachtiar, Doni 2012. Pengaruh Motivasi dan Lingkungan Kerja Terhadap kinerja Karyawan. Yogyakarta: BPFE.

Badan Pusat Statistik, 2018. Kabupaten Manokwari Dalam Angka.

Ghozali, 2006. Aplikasi Analisis Multivariate dengan program SPSS: Badan Penerbit Universitas Diponegoro, Semarang.

Husein, Umar 2005. Metode Penelitian. Jakarta: Salemba Empat.

Santoso, W.J. 2000 Prinsip Pemasaran, Jakarta: Penerbit Erlangga.

Sugiyono, 2008. Metode Penelitian Kualitatif dan R\&D. Bandung: Alfabeta. 